\title{
NOTIONAL PERMEABILITY
}

\author{
Kik, R. ${ }^{1}$, Van den Bos, J.P. ${ }^{2}$, Maertens, J. ${ }^{3}$, Verhagen, H.J. ${ }^{4}$, Van der Meer, J.W. ${ }^{5}$
}

\begin{abstract}
Different layer design of a rock slope and under layers has a large effect on the strengths on the rock slope itself. In the stability formula developed of VAN DER MEER [1988] this effect is represented by the term Notional Permeability with symbol P. A more open, or permeable, structure underneath the armour layer has the ability to dissipate more wave energy and therefore requires less weight of the armour layer. The influence of this parameter is thus very important in economic sense. Up until now only three configurations have been tested. In practice often intermediate structures were designed which do not correspond to the standard situations. P-values then have to be estimated in comparison with the known structures, which gives some uncertainty around the P-value. Therefore there is the demand for more validated values of the notional permeability representing other structures. During this study physical scale modelling is used to produce a value of $\mathrm{P}$ for a new structure.

Keywords: rubble-mound breakwater; notional permeability; van der Meer
\end{abstract}

\section{Introduction}

For the design of the armour layer of randomly placed rubble mound breakwaters usually the choice is made between two formulas; the Hudson formula which is the result of studies in 1953, 1959 and 1961, or the other one which is the well-known formula of Van der Meer introduced in 1988.

The Van der Meer formula has a lot of differences with respect to the Hudson formula. The main difference is in the number of coefficients used, which indicates that the Van der Meer formula is much more detailed. The Van der Meer formula takes the breaker parameter, number of waves and damage level into account. It also contains a factor P which describes the "notional permeability" of the breakwater. This factor is based on the fact that a more permeable structure dissipates more energy and hence requires less heavy armouring. Its value depends on the different layer designs of the breakwater.

The notional permeability (P) was empirically determined by VAN DER MEER [1988] for three different standard situations, to be exact the $\mathrm{P}=0.1, \mathrm{P}=0.5$ and $\mathrm{P}=0.6$. The fourth one with a filter layer and a core is determined by interpolation of the tested configurations $(\mathrm{P}=0.4)$. The figure below shows these four standard situations.

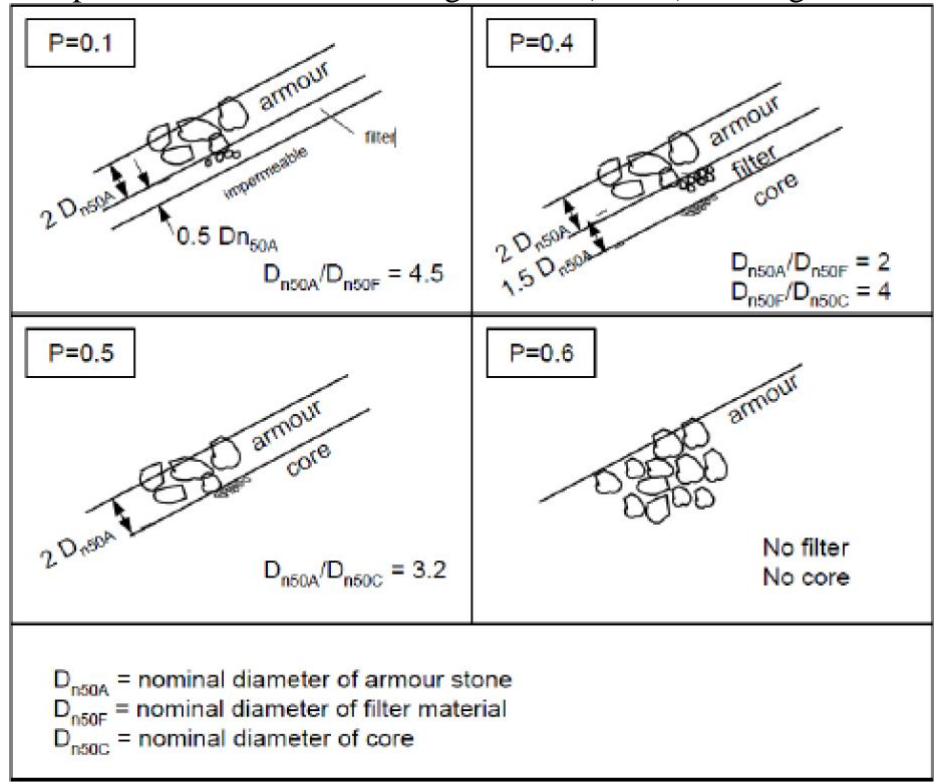

Figure 1 Notional permeability as described by VAN DER MEER [1988]

In practice however these standard situations from the figure above do not always apply. Often intermediate configurations between the first and the second are designed (structures with a thick filter layer and an

\footnotetext{
${ }^{1}$ Van Oord, Schaardijk 211, Rotterdam, $3063 \mathrm{NH}$, The Netherlands

${ }^{2}$ Royal Boskalis Westminster, Rosmolenweg 20, Papendrecht, 3350 AE, The Netherlands

${ }^{3}$ DEME, Scheldedijk 30, Zwijndrecht, Belgium

${ }^{4}$ Delft University of Technology, Stevinweg 1, Delft, The Netherlands

${ }^{5}$ Van der Meer consulting, Voorsterweg 28, Heerenveen, The Netherlands
} 
impermeable core with geo-textile) which do not completely correspond with one of the four standard configurations for which the $\mathrm{P}$ value is known. Despite the fact that the influence of the permeability of the structure is very large, there is still no easy way to calculate the notional permeability of a given cross-section of a rubble mound breakwater.

During this study the method of empirical testing is used to determine the value of $\mathrm{P}$ for a new structure.

\section{Van der Meer stability formula}

The base of this study is the stability formulae of Van der Meer. In modern literature (ROCK MANUAL [2007] and BREAKWATERS AND CLOSURE DAMS [2009]) the stability formulae are often written with the coefficients 6.2 and 1.0 as the stochastic variables $\mathrm{c}_{\mathrm{pl}}$ and $\mathrm{c}_{\mathrm{s}}$.

$$
\begin{array}{ll}
\frac{H_{s}}{\Delta d_{n 50}}=c_{p l} P^{0.18}\left(\frac{S}{\sqrt{N}}\right)^{0.2} \xi_{m}{ }^{-0.5} & \text { (plunging waves) (1) } \\
\frac{H_{s}}{\Delta d_{n 50}}=c_{S} P^{-0.13}\left(\frac{S}{\sqrt{N}}\right)^{0.2} \xi_{m}{ }^{P} \sqrt{\cot a} & \quad \text { (surging waves) (2) }
\end{array}
$$

In which:

$\mathrm{H}_{\mathrm{s}}=$ Significant wave height

$\mathrm{c}_{\mathrm{pl}}=$ Parameter for plunging waves $\mu=6.2 \sigma=0.4$

$\mathrm{c}_{\mathrm{S}}=$ Parameter for surging waves $\mu=1.0 \sigma=0.08$

$\mathrm{P}=$ Notional permeability

$\mathrm{S}=$ Damage number

$\mathrm{N}=$ Number of waves

$\xi_{\mathrm{m}}=\frac{\tan (\alpha)}{\sqrt{s_{m}}}$ Breaker parameter

$\mathrm{s}_{\mathrm{m}}=$ Wave steepness calculated with the mean wave period

Van der Meer was the first one who made a distinct difference between two types of breaking waves with respect to the stability of the breakwater. Namely plunging and surging waves. The classification between the different types of breaking waves is made on the basis of the breaker parameter, which on its turn depends on the wave steepness and the slope of the structure.

The transition relation is then described as:

$$
\xi_{\text {critical }}=\left(\frac{c_{p l}}{c_{s}} * P^{0.31} \sqrt{\tan (\alpha)}\right)^{\frac{1}{P+0.5}}
$$




\section{Test setup}

In this study three different structures were tested. Two reference structures, used to check the method of testing and analysis and a new structure which was not physically tested before. The first reference structure is the structure with an armour layer on top of a permeable core. Van der Meer found a permeability of $\mathrm{P}=0.5$ for this structure. The second structure was the structure with armour layer on top of a thin filter layer and an impermeable core, Van der Meer found a permeability of $\mathrm{P}=0.1$ for this structure.

The new structure consisted out of an impermeable core, covered by a thick filter layer with a relatively small stone size, followed by a coarse filter layer and finally an armour layer, see figure 4 . This structure represents the real life situation in which a core of sand is placed and covered by a geo-textile. Then quarry run is used to create the desired slope of the structure and the coarser filter layer is used to make the filter geometrically closed. Finally, like all the other structures, the double armour layer is used to withstand the wave impact. The new structure has the same stone size ratios between the different layers as the $\mathrm{P}=0.4$ structure defined by Van der Meer (figure 1), but now with the presence of an impermeable layer. The layer thickness is Armour layer= $2 * \mathrm{~d}_{50 \text { armour }}$, first filter layer $=1 * \mathrm{~d}_{50 \text { armour }}$, second filter layer $=2 * \mathrm{~d}_{50 \text { armour }}$

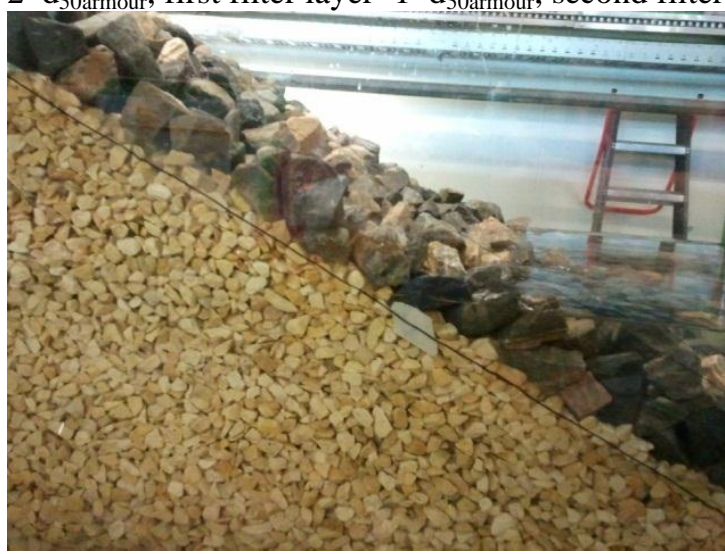

Figure 2 Structure 1, $P=0.5$
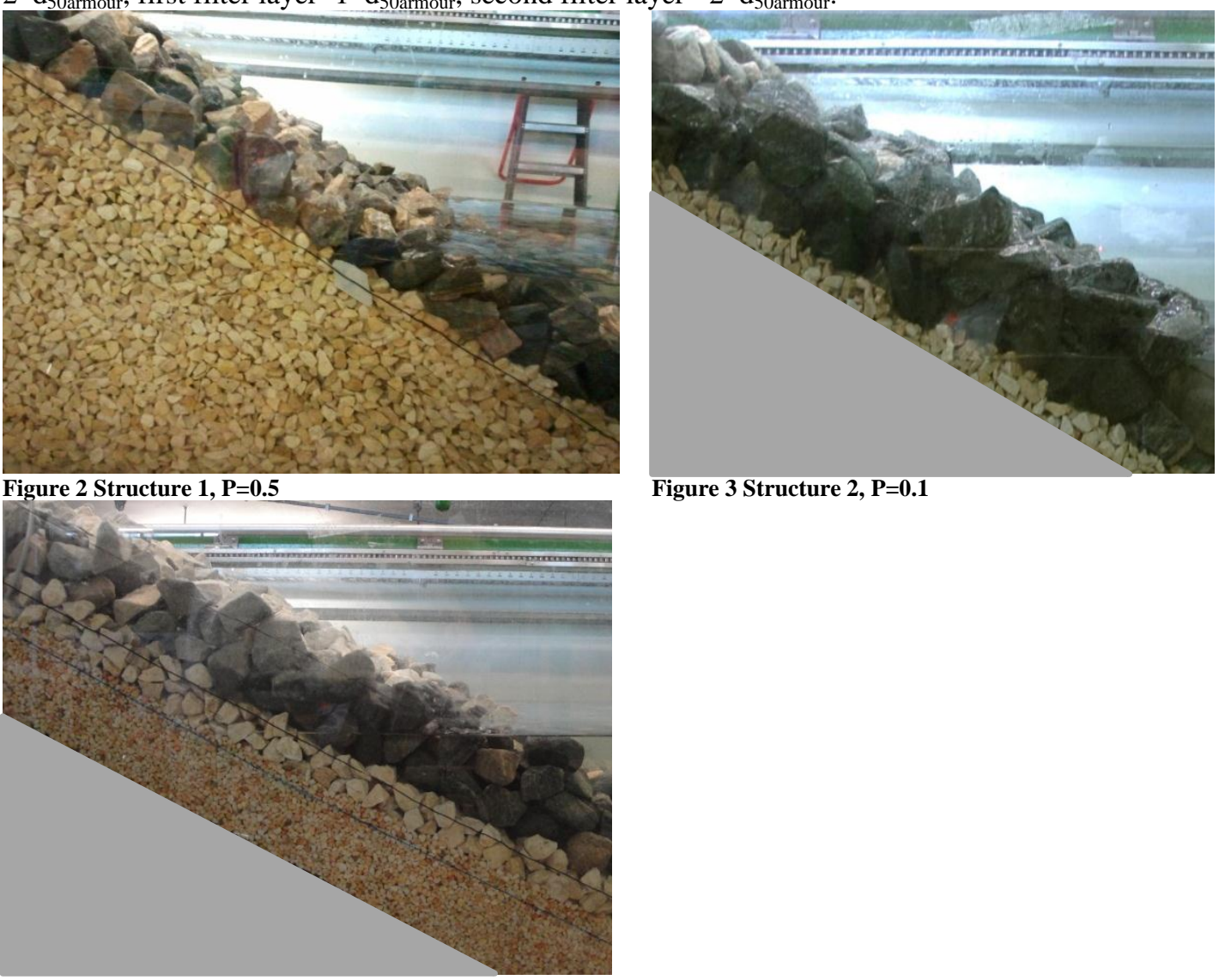

Figure 3 Structure 2, $\mathrm{P}=\mathbf{0 . 1}$

Figure 4 Structure 3, P=0.37

To achieve comparable results with the original research of Van der Meer most of the parameters used in this experimental study were equal to the original research of Van der Meer. Therefore a Pierson- Moskowitz spectrum was used. Every test consisted out of 3000 waves. The armour layer had in all the experiments a stone size of $\mathrm{D}_{\mathrm{n} 50}=0.04 \mathrm{~m}$. The water depth in the flume was $0.65 \mathrm{~m}$, the significant wave heights varied from about $0.1 \mathrm{~m}$ to $0.15 \mathrm{~m}$ the mean period varied from roughly 1 second to 4 seconds. During a test series of a structure a variation was made in breaker parameter, by varying the wave period whilst keeping the wave height constant. The armour layer of the 1:2 sloped structure was rebuild after every test to ensure equal starting conditions for every test and to prevent the effect of armouring of the top layer. 
The value of $\mathrm{P}$ is determined by measuring and fixating all the variables (wave conditions, damage, number of waves etc.) in the stability formulae 1 and 2 for the entire test series of a certain structure. The damage is calculated for a certain value of $\mathrm{P}$ and compared to the measured damage. The value of $\mathrm{p}$ with the lowest RMSE was considered to be the best value of $\mathrm{P}$ for that structure.

Profile measurements of the initial structure and the structure after conduction the test is taken every 5 centimetres. These measurements are averaged and deducted from each other to determine the total eroded area. By determining the total eroded area and dividing this value by the square of the armour size the damage number $\mathrm{S}$ is acquired.

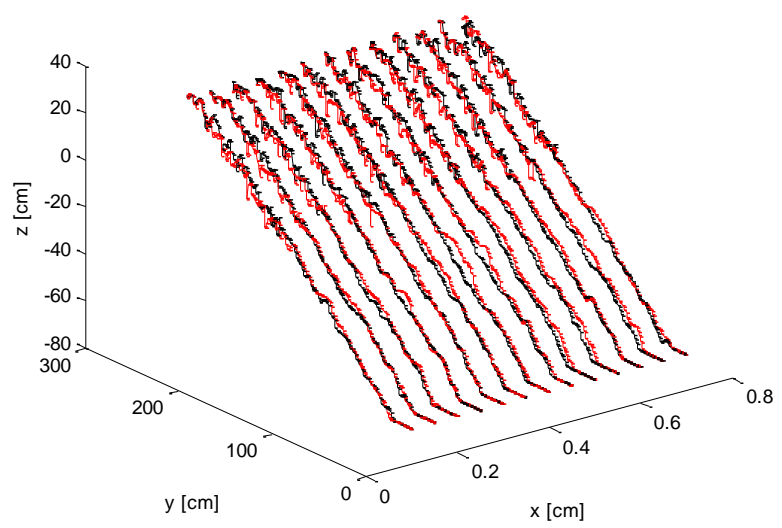

Figure 5 Measured profiles every $5 \mathrm{~cm}$

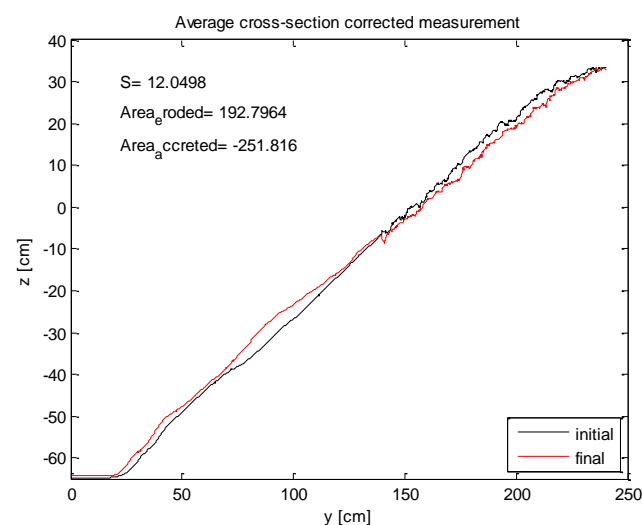

Figure 6 Measured profiles averaged 
Data analysis

The test results are analysed by comparing the calculated and the measured damage with means of the Van der Meer stability formulae. For the entire data set per structure the value of P, resulting in the lowest RMS error was considered to be the best fit for the notional permeability.

The results of the first structure with a permeable core are shown in figures 7 and 8 . The second figure shows the results in combination with the data points of the original research of Van der Meer [1988] and plotted as a function of the breaker parameter. The value of P resulting in the lowest RMSE was $\mathrm{p}=0.55$

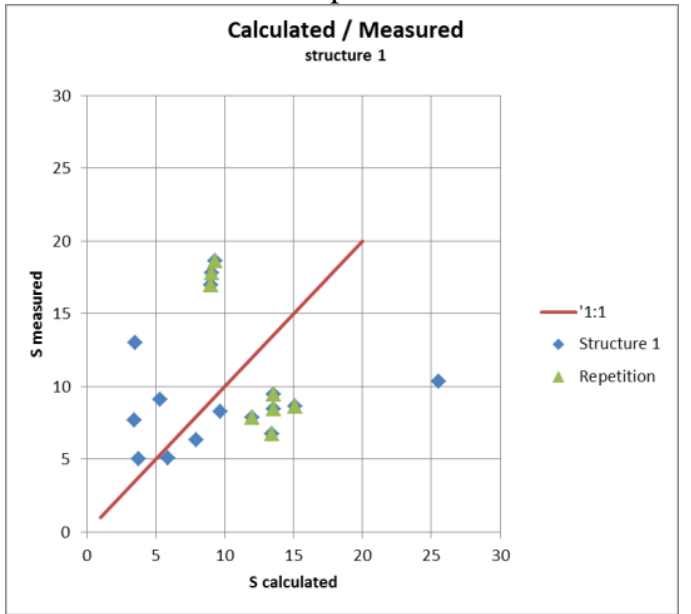

Figure 7 Data analysis structure 1

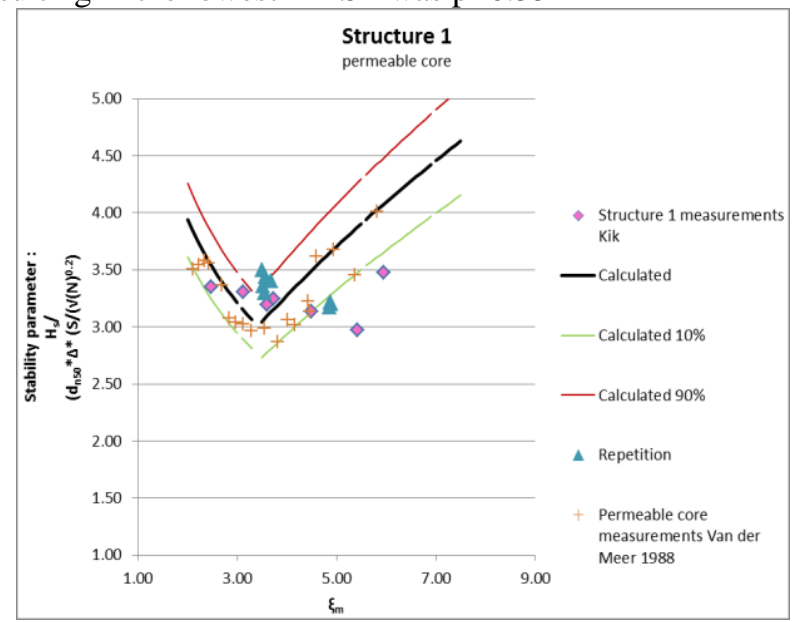

Figure 8 Stability parameter figure structure 1

The second structure, which has an impermeable core, shows the following results. The measured results agree very well with the calculated results. Also when the data point are compared to the data points of Thompson and Shuttles[1975] and Van der Meer[1988] one can see that the values are within the scatter of the earlier studies. The value with the lowest RMSE was a value of $\mathrm{p}=0.08$.

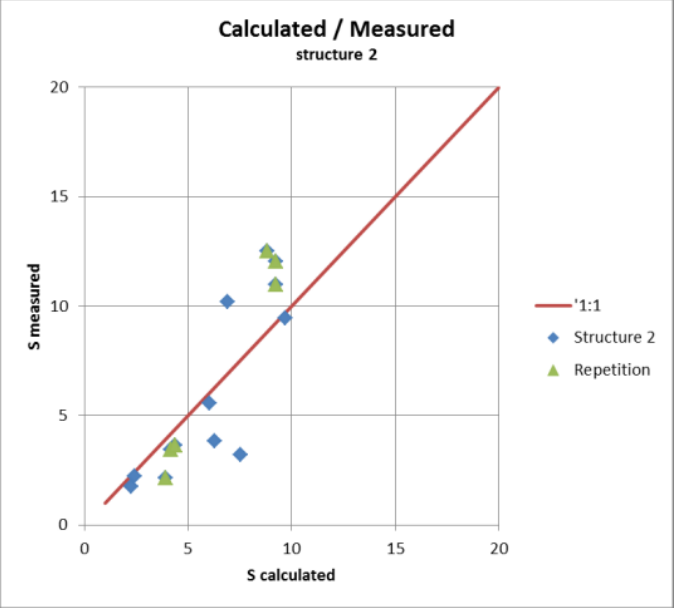

Figure 9 Data analysis structure 2

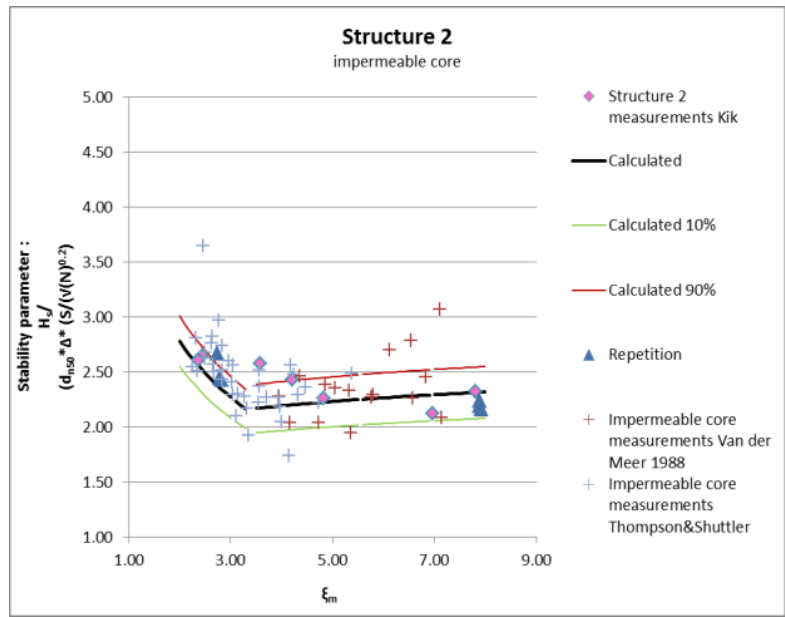

Figure 10 Stability parameter figure structure 2

Based on the fact that both reference tests show a well agreeing with the original research it can be said that the test execution and analysis show similar results as the original research, and therefore produce comparable results. 
The third structure, which has never been tested before, shows the following results. In total 17 tests (including repetition tests) are carried out on the new structure with a 1:2 slope. The lowest value of the RMSE is found with a notional permeability of $p=0.37$. A remarkable fact is that the value is very close to the value of the $p=0.4$ structure, which has no impermeable core and is never tested before.

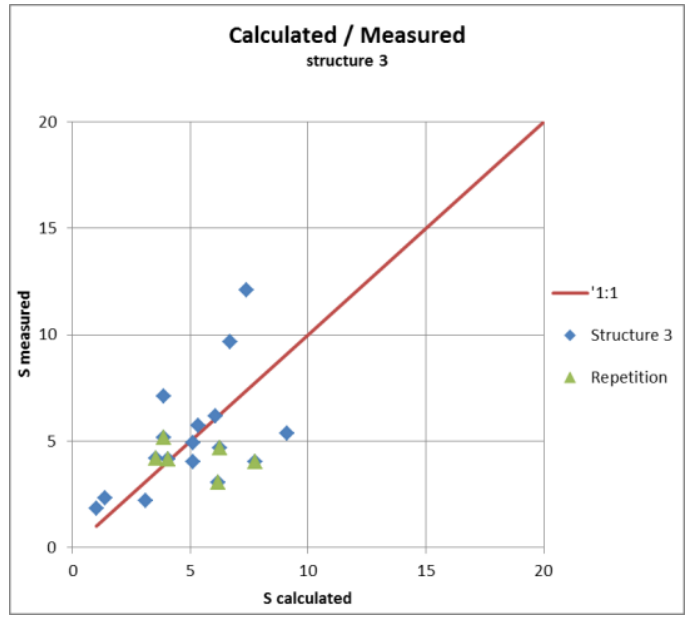

Figure 11 Data analysis structure 3

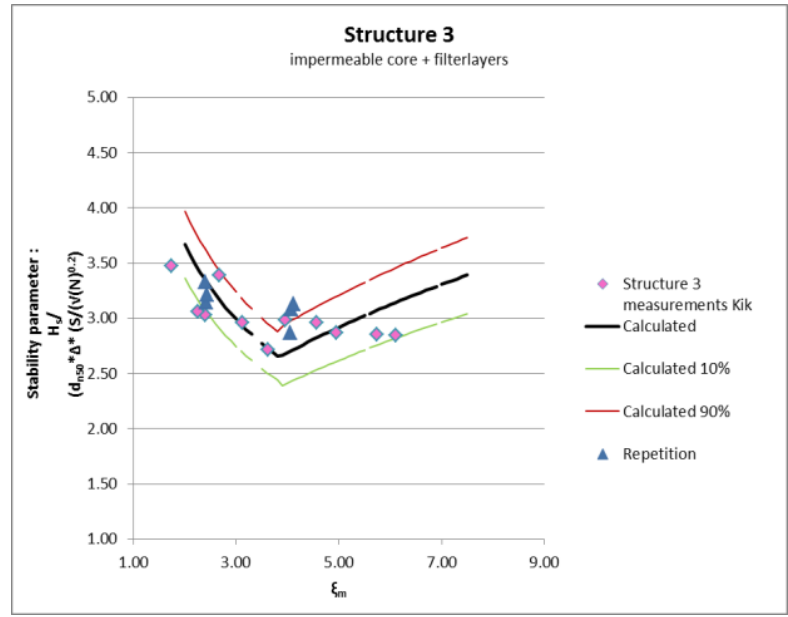

Figure 12 Stability parameter figure structure 3

\section{Conclusions}

This research has shown that the empirical method of determining the value for the notional permeability provides reliable results. This has been proven by the execution of two reference structures of which the value is known. The produced results which are located within the spreading of the original research of Van der Meer [1988] and Thompson\&Shuttler [1975] results into a value of p close to the defined values by Van der Meer [1988]. The new structure with stone size ratios of the $p=0.4$ structure, but with the presence of an impermeable core after two filter layers, shows a notional permeability of $p=0.37$. Due to the limited number of tests a value of $\mathrm{p}=0.35$ is recommended for practical use.

\section{REFERENCES}

Broekhoven, P.J.M. 2011. The influence of armour layer and core permeability on the wave run up, Delft University of Technology.

Burcharth, H.F. et al. 1999. Scaling of core material in rubble mound breakwater model tests, COPEDEC V Cape Town South Africa.

Burcharth, H.F. Andersen, O.H. 1995. On the one dimensional steady and unsteady porous flow equations, Coastal engineering 24, 233-257.

CIRIA, CUR, CETMEF. 2007. The rock manual. The use of rock in hydraulic engineering, C683, CIRIA.

D'Angremond, K Verhagen, H.J. Roode van, F. 2009 Breakwaters and closure dams, VSSD Delft

Gent van, M.R.A. 1995. Wave Interaction with Permeable Coastal Structures, Delft university of Technology

Holthuijsen, L. H. 2008. Waves in oceanic and coastal waters, Cambridge University Press

Heij de, J.E.J. 2001. The influence of structural permeability on armour layer stability of rubble mound breakwaters, Delft university of Technology

Hughes, S.A. 1993. Physical models and laboratory techniques in coastal engineering, World Scientific Publishing Co.

Jumelet, H.D. 2010. The influence of core permeability on armour layer stability, Delft university of Technology

Kik, R. 2011. The notional permeability of breakwaters, Delft university of Technology

Mertens, M. 2007. Stability of rock on slopes under wave attack, Delft university of Technology

Papadopoulos, D 2011. Damage on rock slopes under wave attack, Delft university of Technology

Schiereck, G.J. 2004. Introduction to Bed, bank and shore protection, VSSD Delft

Thompson and Shuttler 1975. Riprap design for wind-wave attack, Hydraulic research station Wallingford

Troch, P 2000. Experimentele studie en numerieke modellering van golfinteractie met stortsteen golfbrekers, Universiteit van Gent

Van der Meer, J.W. 1988. Rock slopes and gravel beaches under wave attack, Delft university of Technology 
Vilaplana Domingo, A.M. 2010. Evaluation of the volume-exchange model with Van der Meer laboratory tests results, Delft university of Technology 